Nowadays physicians are under economic pressure; therefore therapeutic decisions based on safety, efficacy, and the effectiveness of the medication also require economic analysis. The aim of this review is to discuss data concerning the cost-effectiveness of drug therapy in patients with hormonally active pituitary adenomas, namely growth hormone, adrenocorticotropic hormone, thyroidstimulating hormone-secreting pituitary adenomas, prolactinoma and pituitary incidentaloma.

In acromegalic patients using lanreotide is cheaper for health care payers and more convenient for physicians and patients because of the opportunity for self/partner injections, lower clogging risk and possibility of longer intervals between injections, while the efficacy is comparable with octreotide. Patients with prolactinomas should be treated with novel dopamine agonists, such as cabergoline or quinagolide, however bromocriptine still remains a cheaper and almost as effective alternative.

There are no easy methods or algorithms, but in general, extracting the maximum value from the investment in treatment is essential.

Key words: pharmacoeconomics, lanreotide, octreotide, acromegaly, prolactinoma, ACTH-secreting pituitary adenoma.

\section{Pharmacoeconomic aspects of the treatment of pituitary gland tumours}

\author{
Jerzy Sowiński, Nadia Sawicka, Katarzyna Piątek, Ariadna Zybek, \\ Marek Ruchata
}

Department of Endocrinology, Metabolism and Internal Medicine, Poznan University of Medical Sciences, Poland

\section{Introduction}

The prevalence of pituitary gland tumours is a matter of recent debate. In the meta-analysis based on data extracted from anatomical studies (including autopsies and imaging studies) pituitary adenomas were found in approximately $17 \%$ of the population [1]. However, a community-based, crosssectional study performed among 81149 subjects established the prevalence of pituitary adenomas as 77.6 cases per 100000 inhabitants [2]. These results are supported by a population-based study recently performed in Malta which established a prevalence rate of pituitary gland tumours of 75.67 per 100000 people [3]. The clinical relevance of pituitary adenomas depends on their size, location, hormonal hyper- or hyposecretion, and visual field loss. Their potentially serious effects require a diagnostic approach based on physical examinations, laboratory tests, and imaging procedures.

In general, a patient with a pituitary adenoma requires treatment of hormonal or visual abnormalities. Pituitary gland tumours resulting in hypersecretion may lead to hyperprolactinemia, acromegaly, and Cushing's disease. The treatment of choice for acromegaly and Cushing's disease is transsphenoidal surgery. Pituitary irradiation is also a therapeutic option when other methods are unsuccessful. Recently, modern medications are also available for treatment. Decisions concerning therapeutic modalities require an individual approach to every patient. However, nowadays physicians are under economic pressure, so therapeutic decisions based on safety, efficacy, and the effectiveness of the medication also require economic analysis. The aim of the paper is to discuss data concerning the cost-effectiveness of drug therapy in patients with pituitary adenomas.

\section{Growth hormone-secreting pituitary adenoma}

Acromegaly is a rare disease, which is characterised by an elevated level of growth hormone (GH). In the prevalent cases (nearly 99\%), acromegaly is caused by benign, slowly growing pituitary adenoma, which produces excess $\mathrm{GH}$. The annual incidence of acromegaly was estimated as 3.3 cases/million. The worldwide prevalence is approximately 60 per million. Although the incidence is not very high, the costs of lifelong care and treatment of acromegaly and its comorbidities are a noticeable burden for health care payers [4-6]. Due to a slow and insidious onset, the diagnosis is usually delayed and established 7-10 years after the first symptoms occurred [7]. This disease has a chronic and debilitating nature. Untreated disease reduces the life expectancy of patients by approximately 10 years. The most likely cause of death is cardiovascular failure [8, 9]. It is worth mentioning that the decreased GH level and appropriate for age insulin-like growth factor-I (IGF-1) concentration can potentially equalize the mortality between patients with acromegaly and the general population [4]. The patients quality of life (QOL) is decreased, not only due to treatment reasons but also because of immutable 
changes including alternation of patient's appearance, which cannot be cured.

Acromegaly is accompanied by many others disorders. Impaired glucose tolerance occurrs in $16-46 \%$ of patients. Diabetes mellitus prevalence is higher and is estimated at 19-56\% of cases. Cardiovascular effects include: arterial hypertension, arrhythmia and concentric biventricular hypertrophy. At diagnosis, arthropathy occurs in up to $70 \%$. Sleep apnoea, among which the obstructive type is the most frequent, brings an additional problem to the patients [4, 10].

Decisions concerning the strategy of management must be individualized for each acromegalic patient. There are some treatment options - surgery, radiotherapy, pharmacotherapy with somatostatin analogues, GH receptor antagonist, and dopamine agonists - which can be used as monotherapy or combined [4, 9]. The goal of medical management is to achieve optimal disease control which is defined as a mean $\mathrm{GH}$ level less than $2.5 \mathrm{ng} / \mathrm{ml}$, GH level less than $1 \mathrm{ng} / \mathrm{ml}$ during an oral glucose tolerance test (OGTT), and age- and sexadjusted normal IGF-1 level. However, when pegvisomant is administered, only the IGF-1 level remains as a biochemical marker of disease control [11, 12].

\section{Pharmacological treatment of acromegaly}

Among the various methods of treatment, pharmacological management plays an important role in controlling acromegaly. There is a wide range of therapeutic indications: as first-line therapy when the patient prefers to be treated using pharmacological medications and there are contraindications for surgery, and possibly, in very old age. As second-line therapy, when the effect after surgery is not satisfactory, and after radiotherapy until the curing effect occurs $[12,13]$.

Plöckinger noted that the criteria for the initiation of medical therapy should include not only the elevated markers of biochemical control but also the clinical activity of acromegaly and the patient's subjective activity of disease reported in the AcroQOL questionnaire. (The AcroQOL is an acromegaly specific questionnaire designed to assess the quality of patients' lives) $[9,12]$.

Primary medicaments used to control acromegaly are somatostatin analogues (SA). Current guidelines for acromegaly management recommend using SA when there is a low probability of cure by performing surgery; after surgery has failed and no biochemical control was achieved; before surgery, when there are severe comorbidities, which may be improved to perform surgery more safely (pre-surgical therapy is still a matter of debate); or after radiotherapy to achieve disease control, until the effect of radiotherapy is satisfactory $[6,12-14]$.

There are two slow-release SA approved by the U.S. Food and Drug Administration (FDA): lanreotide (Somatuline AUTOGEL ${ }^{\circledR} 60,90,120 \mathrm{mg}$ ) and octreotide (Sandostatin LAR ${ }^{\circledR}$ 10, 20, $30 \mathrm{mg}$ ) [15]. Numerous studies have been performed to compare them. Both lanreotide and octreotide have approximately 40-60\% efficacy in achieving a biochemical control of acromegaly [12-14]. Moreover, both medications are well tolerated, lead to symptom relief and are effective in reducing tumor size by at least $20 \%$ in approximately $75 \%$ of patients suffering from this disease $[13,14,16]$. So far, individual results of therapy are not predictable.

Many symptoms of acromegaly such as headaches, hyperhidrosis, sleep apnoea, arthritic pain and the occurrence of carpal-tunnel syndrome may be relieved during SA therapy [12]. Mortality is decreased due to positive effects on the cardio-vascular system and renal structure and function. Conversely, the quality of life $(\mathrm{QOL})$ of patients, even with controlled disease is not improved [9].

Lanreotide and octreotide are synthetic analogues of somatostatin which are designed to connect with sst2 and sst5 with high affinity $[6,12,15]$. Due to the location of somatostatin receptors not only in the pituitary gland but also in the gastrointestinal tract and pancreas, side effects may be as follows: nausea/vomiting, cholelithiasis, abdominal discomfort, diarrhea, and reduced glucose tolerance. Moreover, injection site reactions such as erythema or swelling may occur. Local side effects can be avoided by warming drugs to room temperature before injection $[9,12,13,16]$.

The half-life of somatostatin is approximately 2 minutes, which is the reason why its use in treatment was rejected. SA have a noticeably prolonged half-life of up to 2 hours. Sandostatin LAR $^{\circledR}$ and Somatuline AUTOGEL ${ }^{\circledR}$ due to a long-acting/slow release form are able to guarantee a suppressing level of SA in serum from 4 to 8 weeks respectively [12]. Pharmacokinetics studies on lanreotide showed that after an injection of depot formulation a stable linear release profile was observed. The mean absolute bioavailability was approximately $70 \%$ for all available doses. With increasing doses 60 , 90 and 120 mg increasing lanreotide concentrations in serum were achieved. After single administration of Somatuline AUTOGEL ${ }^{\circledR} 120 \mathrm{mg}$ the effective concentration level was observed in 56 days following the injection and it was confirmed in many clinical trials [6, 15, 17-22]. Recently the FDA has approved extended dosing intervals for lanreotide and now this SA is administered every 4 to 8 weeks [6]. Octreotide has pharmacodynamics which do not allow an extended dosing interval and the FDA has approved an interval of 4 weeks for this medicament [23].

\section{Aspects of pharmacoeconomics in acromegaly treatment}

There is a publication from 2006, which describes the whole cost of management in one patient with acromegaly. Orthopaedic surgery and dental care were included. The total expenditure was approximately $\$ 1000000$, from before the diagnosis up to 25 years later [8]. In Brazil a study comparing the costs of treatment using lanreotide and octreotide was carried out; however, it compared Somatuline $L A^{\circledR}$ and Sandostatin $L A R^{\circledR}$. Somatuline AUTOGEL ${ }^{\circledR}$ was not available in Brazil in 2008 [24]. Marko et al. calculated the annual cost of treatment using SA. To compare the costs, the average dose of lanreotide was assumed as $103 \mathrm{mg} / 4$ weeks and of octreotide as $24 \mathrm{mg} / 4$ weeks. The annual costs of lanreotide and octreotide were $\$ 41216$ and $\$ 43526$, respectively. Somatuline AUTOGEL ${ }^{\circledR}$ was cheaper in use, at the same efficacy of $60 \%$ for both medications. The authors calculated that the illness is diagnosed at an average patient age of 40 years and if treated successfully, the illness does not shorten the 
patient's lifetime. Assuming that the life expectancy in the USA is 78.3 years (data from 2010), the average time of treatment for a single patient is 38.3 years, and the costs are: \$ 1578567 if lanreotide is administered and \$1 667052 if octreotide is used. The calculation was published in 2010 [9].

As described earlier, lanreotide and octreotide are very similar except for two very important things: the means of application and the opportunity to exceed the time interval between injections for lanreotide. Somatuline AUTOGEL ${ }^{\circledR}$ is a medication which is sold in ready-to-use prefilled-syringes with a low volume of liquid $(0.3-0.5 \mathrm{ml})$ for deep subcutaneous injection $[15,16]$.

Adelman et al. presented results from their research which was designed to compare the administration of lanreotide and octreotide by nurses from Europe and the USA. All points were given on a 10-point scale. For nurses, the most important attributes of medicaments were: the confidence that patient received the full dose (9.5), high product efficacy (9.4), appropriate safety features (9.4), low risk of clogging (8.8) and convenient preparation and injection (8.8). Somatuline AUTOGEL ${ }^{\circledR}$ is in a device which is transparent and thus, enables a check as to whether the whole dose was delivered. $70 \%$ of nurses appreciated the fact that the device has an automated needle guard. During 3 years preceding the research, $69 \%$ of the nurses had experienced or had heard about clogging with SA; 99\% (440/443) occurring when octreotide was being administered. The time of injection preparation and administration was approximately one minute vs. five and a half minutes for lanreotide and octreotide, respectively [23]. Less risk of clogging and a shorter time to prepare and perform the injection are the advantages which make Somatuline AUTOGEL ${ }^{\circledR}$ more convenient to use.

Considering the risk of clogging in the previously described research, Marty et al. compared the costs of administration of Somatuline AUTOGEL ${ }^{\circledR}$ and Sandostatin $L A R^{\circledR}$ in France, Germany and the United Kingdom. During the research there were no clogging incidents when lanreotide was injected, whereas clogging occurred in $2.5 \%$ of administrations of octreotide. The authors calculated the costs per successful injection for both medicaments in varied doses. Somatuline AUTOGEL ${ }^{\circledR}$ was cheaper than Sandostatin $L A R{ }^{\circledR}$ by $€ 13-45$, $€ 52-108$ and $€ 127-151$ for France, Germany and the United Kingdom, respectively. In France both drugs are the same price, as opposed to Germany and the United Kingdom, where lanreotide is cheaper. To compare cost savings, pounds were converted to euros based on the mean exchange rate in 2010. To calculate the annual cost savings for one patient Somatuline AUTOGEL ${ }^{\circledR} 90 \mathrm{mg}$ and Sandostatin $L A R{ }^{\circledR} 20 \mathrm{mg}$ were chosen. The results were as follows: $€ 356.4$, $€ 929.5$ and $€ 1457.5$ for France, Germany and the United Kingdom, respectively. These numbers were also multiplied by the number of acromegalic patients treated with SA for each country. The annual cost savings for health care payers could be as high as $€ 948$ 236, € 3176618 and $€ 3645213$ in France, Germany and the United Kingdom, respectively [15].

In contrast to octreotide, which is designed for intramuscular injections, lanreotide is adjusted for self-administration [12]. Approximately $20 \%$ of patients treated with SA, if asked, were willing to accept self-injection and another $20 \%$ partner-injection $[6,13]$. The efficacy and safety of self/partner injections were compared with injections performed by a healthcare professional and there were no significant differences $[13,25]$. A prefilled syringe which requires no reconstitution, allows $100 \%$ of willing patients/partners to perform the injection correctly after being trained by a healthcare professional $[16,25]$. After the end of the research, $88 \%$ of them preferred to continue the self/partner method of administration. The most important advantages of this form of treatment were: the opportunity to save time, lack of necessity to travel to hospital, and increased patient independence $[13,25]$.

From an economical point of view, less frequent clinical visits for injections could save $€ 65$ per injection (data for Sweden 2012) [25]; indirect costs are also reduced. Patients do not need to spend time and money to travel to hospital. Currently, self-administration of Somatuline AUTOGEL ${ }^{\circledR}$ is approved in most European countries [16].

Pharmacodynamics of lanreotide allows the dose interval to be extended to even up to 8 weeks. Abrams et al. noticed the opportunity to reduce the costs of the management of patients with acromegaly. The authors exceeded the intervals between lanreotide injections for the patients with controlled disease up to 6 weeks. This provided the effectiveness of treatment in $78 \%$ of patients, although the weekly dose was diminished. The annual cost of treatment was decreased also. Even when the weekly dose was maintained (60 mg per 4 weeks was switched to $90 \mathrm{mg}$ per 6 weeks), the annual cost decreased from $€ 11316$ to $€ 9024$ [22]. In the research reported by Plöckinger, Sandostatin LAR ${ }^{\circledR}$ 10, 20, $30 \mathrm{mg}$ administered every 4 weeks was changed to Somatuline AUTOGEL ${ }^{\circledR} 120 \mathrm{mg}$ injected every 8, 6 and 4 weeks, respectively. There were no significant differences in $\mathrm{GH}$ and IGF-1 concentrations between the medicaments. Hormonal control was achieved in $63.6 \%$ of patients with intervals between injections lasting for 8 and 6 weeks. Almost $50 \%$ of well-treated patients had injections less frequently then every 4 weeks. With prolonged intervals, the investigators and patients' preference for lanreotide grew. Among $71.4 \%$ patients treated with lanreotide every 8 weeks, investigators declared that they would use this frequency of administration in the future. In the group with an interval of 6 weeks, the preference was $54.5 \%$ vs. 9.1\% for lanreotide and octreotide, respectively. Patients would choose lanreotide compared to octreotide in $57.1 \%$ vs. $14.3 \%, 63.3 \%$ vs. $18.2 \%$ and 11.8 vs. $41.2 \%$ in the 8,6 , and 4 weeks groups, respectively [12]. Carmichael et al. noted that among responders to SA who were not treated with the maximum dose of lanreotide, the interval between injections could be extended to 6 or 8 weeks using lanreotide $120 \mathrm{mg}$. The efficacy of management was similar in each group [16]. The results of the retrospective phase of Lanro-Study were published in 2012 [26]. Lanro-Study is a non-interventional study to assess administration of SA in Poland. All decisions made to change treatment (switching medications, doses and interval time) were not indicated in the study protocol; they only depended on the physicians. The calculated data indicated that lanreotide was injected on average every 5 weeks and 
octreotide on average every 4 weeks. The average monthly cost of treatment using lanreotide and octreotide (in various doses and interval time) was $€ 987.95$ and $€ 1479.23$, respectively. Annual costs were $€ 11855.40$ and $€ 17750.78$, respectively. The annual cost savings connected with using lanreotide was $€$ 5895.38. (The currency of Poland was converted to euro based on the mean exchange rate from January 2013) [26].

To sum up, using lanreotide is cheaper for health care payers and more convenient for physicians and patients because of the opportunity for self/partner injections, lower clogging risk and possibility of longer intervals between injections, while the efficacy is comparable with octreotide.

Pegvisomant (Somavert ${ }^{\circledR}$ ) is the only GH receptor antagonist available in the management of acromegaly. Its mechanism of action is competing with $\mathrm{GH}$ for the $\mathrm{GH}$ receptor and binding with this receptor without activation. Pegvisomant decreases the IGF-1 level, but increases the GH concentration. Hence, to assess the effectiveness of treatment only the IGF-1 level can be used [9, 27-29].

Pegvisomant should be injected subcutaneously in doses of $20 \mathrm{mg}$ per day in monotherapy. This medicament has a high efficacy, approximately 90-97\%, in normalising IGF-1 concentration in serum $[9,12,13,28]$. However, due to the high cost of treatment ( $\$ 68438$ annually) it is indicated for use as a third or fourth option for therapy, when others have failed. Administration of this medicament in addition to SA allows the weekly dose to be decreased to $60 \mathrm{mg}$ once per week, but still, the costs of combined therapy are high (\$ 67189 annually), when lanreotide $120 \mathrm{mg}$ per 4 weeks and Pegvisomant $60 \mathrm{mg}$ per week are administered [9, 12, 27, 28, 30].

Elevation of transaminase levels is a significant adverse reaction during treatment with pegvisomant, noted in more than $10 \%$ of patients. Besides that, headaches, vertigo, tremors, diarrhoea, nausea and pain at the injection site may occur. Pegvisomant has no effect on the gallbladder. It also does not decrease the tumour volume [12, 14, 27-29].

Dopamine agonists (DA) were the first medications used in the treatment of acromegaly. Oral administration and the low costs of treatment are the most important advantages of these drugs [12, 13].

Bromocriptine - the first generation of DA in monotherapy was ineffective; the disease was controlled in only $10 \%$ of patients $[9,14]$. The second generation of DA includes: cabergoline and quinagolide. They are characterised by a longer half-life and fewer side effects than bromocriptine. The current guidelines indicate that only cabergoline should be used for acromegaly. Its efficacy, which was estimated in various studies, varies from $10 \%$ to $40 \%$ in cases of the most modest elevation of IGF-1 level [9, 12, 14].

Nowadays, the use of DA is limited to situations in which the patient prefers oral treatment, after surgery when elevated prolactin (PRL) accompanies elevated GH and IGF-1 levels, and as additional therapy to SA after multiple treatment failures. In the latter case, the normalized GH and IGF-1 occurred in as many as $50 \%$ of patients $[9,14]$.

Due to the $\mathrm{GH}$ receptor being blocked, the $\mathrm{GH}$ concentration in serum rises. Only the IGF-1 level is an indicator of the therapeutic efficacy of DA [12].
Side effects of DA are common. The most frequent are: nausea/vomiting, headaches, vertigo, asthenia, diarrhoea, vasospasm, oedema and sleeping disorders $[9,12]$.

\section{Other pituitary adenomas}

Other types of pituitary adenomas producing PRL, adrenocorticotropin (ACTH) or thyroid stimulating hormone (TSH) may also require medical therapy, including SA.

\section{Prolactinoma}

Prolactinomas are benign pituitary tumours arising from lactotroph cells of the anterior pituitary, representing almost $40 \%$ of all pituitary adenomas. PRL hypersecretion is responsible for many clinical symptoms in female patients, including infertility, menstrual irregularities, reduced libido and vaginal dryness, and in males, including sexual disorders, galactorrhoea and infertility. The so-called "mass effect" may be present, if the large tumour exerts pressure on surrounding tissues, resulting in visual field defects and headaches [31, 32]. Pharmacotherapy remains the widely considered firstline treatment modality for this disorder [33]. Therapeutic options also include observation, transsphenoidal or transcranial surgery and radiotherapy. Since PRL secretion is inhibited by dopamine via the dopamine D2 receptor, normalization of PRL levels is usually achieved with the use of dopamine agonists [31]. Available for over 28 years, this therapy in most cases not only reduces the PRL serum concentration, but also helps to restore gonadal function and decrease the tumor size. The first available and clinically used dopamine agonist was bromocriptine, which has also been the most extensively described and tried over the years. Others, with a longer halflife, such as cabergoline, pergolide and quinagolide have recently become available (in the case of pergolide and quinagolide - not in all countries) [32]. Although the new dopamine agonists are considerably more expensive due to their high efficacy and significantly lower percentage of adverse side effects, they are generally preferred to bromocriptine for the therapy of prolactinomas [34-36]. In a recently published systemic review and meta-analysis of randomized controlled trials comparing cabergoline with bromocriptine, cabergoline provided better rates of normalization for PRL levels and menstruation along with less adverse effects, such as nausea and vomiting and better tumor size reduction than bromocriptine [37]. Gillam et al. in 2006 noted that the normalization of the PRL level was achieved in about $70-80 \%$ of patients treated with bromocriptine, in 80-90\% of those treated with cabergoline and in 70$100 \%$ of patients who were taking quinagolide [31]. Additionally, there is a significantly lower risk of recurrence after cabergoline therapy withdrawal in comparison with bromocriptine. Low doses needed to obtain the normal PRL serum concentration are also in favor of cabergoline [38]. As for drug resistance, it should be mentioned that more patients are resistant to bromocriptine than cabergoline, and $85 \%$ of bromocriptine-resistant subjects responded to cabergoline or quinagolide with a decrease in PRL level [35, 39]. On the other hand, some cases reported recently described cabergoline-resistant patients who positively responded when switched to high doses of bromocriptine. Although novel DA, 
like cabergoline or quinagolide are generally preferred to bromocriptine in the treatment of prolactinomas, mostly because of their better tolerance profile and greater effectiveness, still bromocriptine remains a safe, relatively inexpensive, and well-tolerated alternative [40]. If the cost issue is present and a patient has to pay for the therapy out of his pocket, bromocriptine may and should still be considered, especially, when high doses of drug are needed to reach the normal PRL level. It has been reported that high doses of cabergoline may result in cardiac valve abnormalities, while no such side effects have been described regarding bromocriptine [41]. In conclusion, newly designed and clinically applicable DA are generally preferred in the pharmacotherapy of pituitary PRL-secreting tumours, however, bromocriptine still remains a cheaper and almost as effective alternative, which should be considered when therapy cost is an important issue for a patient.

\section{Adrenocorticotropic hormone-secreting pituitary adenoma}

Pituitary-directed medical treatment of Cushing's disease, i.e. hypercortisolism caused by an ACTH-secreting pituitary tumour, is one of the available medical management types of this disease [32]. Chronic over-production of cortisol by adrenal glands is associated with various features such as metabolic syndrome, hirsutism, easy bruisability, muscle weakness, cognitive dysfunction and mood alterations [42, 43]. Reported significant morbidity and increased mortality of patients with hypercortisolism indicates the need for sufficient disease control [44]. Pituitary surgery is widely recommended as a first-line therapy, with a median remission rate between 60 and $90 \%$. However, a frequent tumour recurrence decreases the rate of successful therapy to $25 \%$. It might be even lower in the case of invisible adenomas and macroadenomas $[45,46]$. Other therapies applied in the past, such radiotherapy or bilateral adrenalectomy (being so-called "last chance treatment") are considered to be not highly effective and have many adverse side effects. For that reason, the urgent need for an effective pharmacological intervention emerges. It might be used especially in case of acute complications of very high cortisol levels, as a balancing treat ment before the surgery to prevent postoperative complications, or in patients with persistent or recurrent disease. It may also be applied as a temporary therapy that decreases serum concentration of cortisol as long as radiotherapy is not yet effective enough. Medical treatment should also be considered when the risk of operation is high, for example in case of macroadenomas, unfavorable location of tumors and general patient's surgery risk [46]. Available treatment modalities include pituitary-targeted, adrenal-blocking and combined therapy [32]. SA, octreotide and novel multireceptortargeted pasireotide were evaluated for their efficacy in lowering the ACTH serum concentration. Although octreotide seems not to be helpful due to the lack of ACTH suppression, many performed studies have indicated the potential of pasireotide. Early reported data pointing to the significant suppression of cell proliferation and inhibition in ACTH secretion in primary cultures of human corticotroph tumors, suggested the possible advantages of this therapy [47, 48]. Since then, many clinical trials have tried to evaluate long-term pasireotide treatment effects, reaching a significant and sustained reduction in ACTH and cortisol levels as well as improvements in blood pressure, BMI, weight and cholesterol in patients with Cushing's disease $[49,50]$. To date, pasireotide has been accepted in Europe for the treatment of patients with Cushing's disease after unsuccessful surgery or for whom surgery cannot be undertaken, becoming the only approved medical therapy that treats the direct source of this disorder. Still, this kind of treatment may be considered only for certain group of patients with tumor recurrence or contraindications for surgical therapy, mostly because of the high cost and persistence of this kind of treatment. The surgical management offers, in not that low percentage of cases, a possibility of full recovery when the pharmacotherapy should be sustained for a long time. Additionally, the disadvantages of this kind of therapy include hyperglycemia-related adverse events in almost $73 \%$ of subjects, making it not only expensive but also not fully safe [49]. Other available reported treatment modalities are adrenalblocking drugs including mitotane, etomidate, metyrapone, ketoconazole and mifepristone, and others, such as retinoic acid and PPAR- $\gamma$ agonists. Interesting are the new possibilities of using dopamine agonists, especially combined with pasireotide. However, further evaluations should be performed to fully confirm the clinical usefulness of this kind of management.

\section{Thyroid-stimulating hormone-secreting pituitary adenoma}

Another rare tumour, accouning for less than $2 \%$ of pituitary adenomas is TSH-producing adenoma. Overgrowth of the thyrotroph cells stimulates the thyroid gland, causing hyperthyroidism [51]. Over the last few years, medical treatment of these tumours with somatostatin analogues has been proposed and introduced, even though the transsphenoidal surgery remains the first-line therapy. The treatment is based on the presence of somatostatin receptors on the cell membrane of thyrotrophs [52]. Available somatostatin analogues, octreotide and lanreotide, provided a decrease in TSH level in over $80 \%$ of cases. Possible future clinical trials with dopamine analogues - bromocriptine and cabergoline - result from detected coexistence of dopamine receptors type 2 on the same cells. The possible clinical correlation between these two receptors may be interesting and requires further evaluation [51, 53].

\section{Pituitary incidentaloma}

Nowadays, more and more pituitary tumours that are clinically non-functioning, are incidentally being found during central nervous system imaging in asymptomatic patients. It has been estimated that the majority of these tumours are actually adenomas producing some, sometimes quite small, amounts of hormones, such as gonadotropins, ACTH, GH, $\mathrm{PRL}$ or TSH, sometimes even more than one at a time. Due to the lack of clinical symptoms, they are called "silent" adenomas $[54,55]$. The Endocrine Society recommends that patients should undergo a complete anamnesis and physical examination. In all patients, laboratory evaluations for 
hormone hypersecretion and hypopituitarism are considered as needed. Additionally, all patients with incidentaloma abutting optic nerves or chiasm on MRI should undergo a formal visual field examination. If the tumour does not need to be surgically removed, a follow-up with a clinical assessment is indicated. Magnetic resonance imaging of the pituitary should be performed after 6 months in the case of macroincidentaloma, and after 1 year in the case of microincidentaloma. If the tumor does not change in time, less frequent subsequent imaging studies are suggested [56]. In the case of detected hormone hypersecretion or hypopituitarism, a proper therapy is indicated. However, there are no available data to support routine medical therapy in non-functioning pituitary tumours. The surgical treatment of nonfunctioning tumours should be considered, according to the newest guidelines, when visual abnormalities such as visual field defect, ophtalmoplegia or lesion abutting the optic nerve on MRI are present. Radiotherapy may be required as an adjunctive method of treatment in progressively growing remnants of the tumor $[56,57]$. Still, appropriate evaluation and follow-up are essential in the management of pituitary incidentalomas. Due to increased sensitivity and frequency of performed central nervous system imaging, the cost of incidentally detected lesions constantly rises. In accordance with Randall et al., who estimated the median cost of conservative management of pituitary incidentalomas, the average expense is $\$ 6215.28$ for males and $\$ 6061.78$ for females. This cost includes both primary and follow-up endocrine serum studies, imaging, and physician fees. All these all expenses have to be borne even if the tumor remains stable and requires no treatment [58]. The potential health benefits of early intervention in incidentally detected masses, which reduce the risk of hypopituitarism and neurological deficits should be evaluated in future guidelines.

\section{Summary}

Undoubtedly, pharmaceuticals and other therapeutic interventions have contributed to the progress in the healthcare of patients with pituitary adenomas. On the other hand, their costs are relevant. Surely, recent focus on reducing the amount of money spent on medical treatment does not translate directly to its costeffectiveness. Pharmacoeconomic evaluation must combine both economic and humanistic aspects of therapy. Potential benefits, the outcome of drug therapy and many other factors should be taken into account for when performing a pharmacoeconomic assessment.

Traditionally, physicians were focused on the clinical outcome of therapy. Nowadays, they are also involved in the economic aspects of therapy. There are no easy methods or algorithms, but in general, extracting the maximum value from the investment in treatment is essential.

The authors declare no conflict of interest.

\section{References}

1. Ezzat S, Asa SL, Couldwell WT, The prevalence of pituitary adenomas: a systematic review. Cancer 2004; 101: 613-9.

2. Fernandez A, Karavitaki N, Wass JA. Prevalence of pituitary adenomas: a community-based, cross-sectional study in Banbury (Oxfordshire, UK). Clin Endocrinol (Oxf) 2010; 72: 377-82.

3. Gruppetta M, Mercieca C, Vassallo J. Prevalence and incidence of pituitary adenomas: a population based study in Malta. Pituitary 2012 Dec 14 [Epub ahead of print].

4. Ben-Shlomo A, Sheppard MC, Stephens JM, Pulgar S, Melmed S. Clinical, quality of life, and economic value of acromegaly disease control. Pituitary 2011; 14: 284-94.

5. Rostad S. Pituitary adenoma pathogenesis: an update. Curr Opin Endocrinol Diabetes Obes 2012; 19: 322-7.

6. Schopohl J, Strasburger CJ, Caird D, ; German Lanreotide Study Group. Efficacy and acceptability of lanreotide Autogel(R) $120 \mathrm{mg}$ at different dose intervals in patients with acromegaly previously treated with octreotide LAR. Exp Clin Endocrinol Diabetes 2011; 119: 156-62.

7. Katznelson L, Atkinson JL, Cook DM, Ezzat SZ, Hamrahian AH, Miller KK; AACE Acromegaly Task Force. American Association of Clinical Endocrinologists Medical Guidelines for Clinical Practice for the Diagnosis and Treatment of Acromegaly - 2011 update: executive summary. Endocr Pract 2011; 17: 636-46.

8. Knutzen R, Ezzat S. The cost of medical care for the acromegalic patient. Neuroendocrinology 2006; 83: 139-44.

9. Marko NF, LaSota E, Hamrahian AH, Weil RJ. Comparative effectiveness review of treatment options for pituitary microadenomas in acromegaly. J Neurosurg 2012; 117: 522-38.

10. Colao A, Ferone D, Marzullo P, Lombardi G. Systemic complications of acromegaly: epidemiology, pathogenesis, and management. Endocr Rev 2004; 25: 102-52.

11. Giustina A, Chanson P, Bronstein MD, Acromegaly Consensus Group. A consensus on criteria for cure of acromegaly. J Clin Endocrinol Metab 2010; 95: 3141-8.

12. Plöckinger U. Medical therapy of acromegaly. Int J Endocrinol 2012; 2012: 268957.

13. Roemmler J, Schopohl J. Clinical experience with lanreotide for the treatment of acromegaly. Exp Rev. Endocrinol. Metab 2012; 7 : 139-49.

14. Katznelson L, Atkinson JL, Cook DM, Ezzat SZ, Hamrahian AH, Miller KK; American Association of Clinical Endocrinologists. American Association of Clinical Endocrinologists medical guidelines for clinical practice for the diagnosis and treatment of acromegaly - 2011 update. Endocr Pract 2011; 17 Suppl 4: 1-44.

15. Marty R, Roze S, Kurth H. Decision-tree model for health economic comparison of two long-acting somatostatin receptor ligand devices in France, Germany, and the UK. Med Devices (Auckl) 2012; 5: 39-44.

16. Carmichael JD. Lanreotide depot deep subcutaneous injection: a new method of delivery and its associated benefits. Patient Prefer Adherence 2012; 6: 73-82.

17. Cendros JM, Peraire C, Troconiz IF, Obach R. Pharmacokinetics and population pharmacodynamic analysis of lanreotide Autogel. Metabolism 2005; 54: 1276-81.

18. Trocóniz IF, Cendrós IM, Peraire C, Ramis J, Garrido MJ, Boscani PF, Obach R. Population pharmacokinetic analysis of lanreotide Autogel in healthy subjects : evidence for injection interval of up to 2 months. Clin Pharmacokinet 2009; 48: 51-62.

19. Kelly P, Maher KT, Chew SL, Monson JP, Grossman AB, Jenkins PJ. A single-center open-label study to investigate the efficacy and safety of repeated subcutaneous injections of lanreotide Autogel in patients with acromegaly previously treated with octreotide. Endocr Pract 2010; 16: 191-7.

20. Lucas T, Astorga R. Efficacy of lanreotide Autogel administered every 4-8 weeks in patients with acromegaly previously responsive to lanreotide microparticles 30 mg: a phase III trial. Clin Endocrinol (Oxf) 2006; 65: 320-6.

21. Ronchi CL, Boschetti M, Degli Uberti EC; Italian Multicenter Autogel Study Group in Acromegaly. Efficacy of a slow-release formulation of lanreotide (Autogel) $120 \mathrm{mg}$ ) in patients with acromegaly previously treated with octreotide long acting release (LAR): an open, multicentre longitudinal study. Clin Endocrinol (Oxf) 2007; 67: 512-519. 
22. Abrams P, Alexopoulou O, Abs R, Maiter D, Verhelst J. Optimalization and cost management of lanreotide-Autogel therapy in acromegaly. Eur J Endocrinol 2007; 157: 571-7.

23. Adelman DT, Burgess A, Davies PR. Evaluation of long-acting somatostatin analog injection devices by nurses: a quantitative study. Med Devices (Auckl) 2012; 5: 103-9.

24. Valentim J, Passos V, Mataveli F, Calabro A. Cost-effectiveness analysis of somatostatin analogues in the treatment of acromegaly in Brazil. Arq Bras Endocrinol Metabol 2008; 52: 1452-60.

25. Johanson V, Wilson B, Abrahamsson A, Jianu C, Calissendorff J, Wall N, Grønbæk H, Florholmen J, Ohberg A, Granberg D. Random ized crossover study in patients with neuroendocrine tumors to assess patient preference for lanreotide Autogel( $\left.{ }^{\circledR}\right)$ given by either self/partner or a health care professional. Patient Prefer Adherence 2012; 6 : 703-10.

26. Orlewska E, Kos-Kudla B, Sowinski J, The retrospective phase re sults of observational study Landro-Study assessing resource uti lization in the population of polish acromegalic patients treated with Somatuline AUTOGEL. New Medicine 2012; 3/2012: 39-46.

27. Moore DJ, Adi Y, Connock MJ, Bayliss S. Clinical effectiveness and cost effectiveness of pegvisomant for the treatment of acromegaly: a systematic review and economic evaluation. BMC Endocr Disord 2009; 9: 20

28. Roelfsema F, Biermasz NR, Pereira AM, Romijn J. Nanomedicines in the treatment of acromegaly: focus on pegvisomant. Int J Nanomedicine 2006; 1: 385-98.

29. Karavitaki N, Wass JA. Pegvisomant: a new treatment modality for acromegaly. Hormones (Athens) 2004; 3: 27-36.

30. Neggers SJ, van der Lely AJ. Combination treatment with somatostatin analogues and pegvisomant in acromegaly. Growth Horm IGF Res 2011; 21: 129-33.

31. Gillam MP, Molitch ME, Lombardi G, Colao A. Advances in the treatment of prolactinomas. Endocr Rev 2006; 27: 485-534.

32. Biller BM, Colao A, Petersenn S, Bonert VS, Boscaro M. Prolactinomas, Cushing's disease and acromegaly: debating the role of med ical therapy for secretory pituitary adenomas. BMC Endocr Disord 2010; 10: 10.

33. Molitch ME, Elton RL, Blackwell RE, Bromocriptine as primary therapy for prolactin-secreting macroadenomas: results of a prospec tive multicenter study. J Clin Endocrinol Metab 1985; 60: 698-705.

34. Maiter D, Primeau V. 2012 update in the treatment of prolactinomas. Ann Endocrinol (Paris) 2012; 73: 90-8.

35. Barlier A, Jaquet P. Quinagolide - a valuable treatment option for hyperprolactinaemia. Eur J Endocrinol 2006; 154: 187-95.

36. Molitch ME. Pituitary tumors: cabergoline versus bromocriptine: a meta-analysis? Nat Rev Endocrinol 2011; 7: 254-5.

37. dos Santos Nunes V, El Dib R, Boguszewski CL, Nogueira CR. Cabergoline versus bromocriptine in the treatment of hyperprolactinemia: a systematic review of randomized controlled trials and meta-analysis. Pituitary 2011; 14: 259-65.

38. Ono M, Miki N, Kawamata T, Makino R, Amano K, Seki T, Kubo O, Hori T, Takano K. Prospective study of high-dose cabergoline treatment of prolactinomas in 150 patients. J Clin Endocrinol Metab 2008; 93: 4721-7.

39. Colao A, Di Sarno A, Sarnacchiaro F, Ferone D, Di Renzo G, Merola B, Annunziato L, Lombardi G. Prolactinomas resistant to standard dopamine agonists respond to chronic cabergoline treatment. J Clin Endocrinol Metab 1997; 82: 876-883.

40. Iyer P, Molitch ME. Positive prolactin response to bromocriptine in 2 patients with cabergoline-resistant prolactinomas. Endocr Pract 2011; 17: e55-8.

41. Molitch ME. The cabergoline-resistant prolactinoma patient: new challenges. J Clin Endocrinol Metab 2008; 93: 4643-5.

42. Findling JW, Raff H. Cushing's Syndrome: important issues in diagnosis and management. J Clin Endocrinol Metab 2006; 91: 3746-53.

43. Arnaldi G, Angeli A, Atkinson AB Diagnosis and complications of Cushing's syndrome: a consensus statement. J Clin Endocrinol Metab 2003; 88: 5593-602.

44. Swearingen B, Biller BM, Barker FG 2nd, Katznelson L, Grinspoon S, Klibanski A, Zervas NT. Long-term mortality after transsphenoidal surgery for Cushing disease. Ann Intern Med 1999; 130: 821-824.

45. Hofland LJ. Somatostatin and somatostatin receptors in Cushing's disease. Mol Cell Endocrinol 2008; 286: 199-205.
46. Fleseriu M, Petersenn S. Medical management of Cushing's disease: what is the future? Pituitary 2012; 15: 330-41.

47. Batista DL, Zhang X, Gejman R, The effects of SOM230 on cell proliferation and adrenocorticotropin secretion in human corticotroph pituitary adenomas. J Clin Endocrinol Metab 2006; 91: 4482-8.

48. Hofland LJ, van der Hoek J, Feelders R, The multi-ligand somatostatin analogue SOM230 inhibits ACTH secretion by cultured human corticotroph adenomas via somatostatin receptor type 5. Eur J Endocrinol 2005; 152: 645-654

49. Bertherat J, Schopohl J, Ludlam WH, Long-term pasireotide use leads to significant and sustained improvements in the signs and symptoms of Cushing disease: 24 -month results from a randomized phase III study. Endocr Rev 2012; 33 (03 MeetingAbstracts): SUN-734.

50. Colao A, Petersenn S, Newell-Price J; Pasireotide B2305 Study Group. A 12-month phase 3 study of pasireotide in Cushing's disease. N Engl J Med 2012; 366: 914-924.

51. Gatto F, Barbieri F, Castelletti L, In vivo and in vitro response to octreotide LAR in a TSH-secreting adenoma: characterization of somatostatin receptor expression and role of subtype 5. Pituitary 2011; 14: 141-7.

52. Ferone D, Gatto F, Arvigo M, Resmini E, Boschetti M, Teti C, Esposito D, Minuto F. The clinical-molecular interface of somatostatin, dopamine and their receptors in pituitary pathophysiology. J Mol Endocrinol 2009; 42: 361-70.

53. Horiguchi K, Yamada M, Umezawa R, Satoh T, Hashimoto K, Tosaka M, Yamada S, Mori M. Somatostatin receptor subtypes mRNA in TSH-secreting pituitary adenomas: a case showing a dramatic reduction in tumor size during short octreotide treatment. Endocr J 2007; 54: 371-378.

54. Young WF Jr, Scheithauer BW, Kovacs KT, Horvath E, Davis DH, Randall RV. Gonadotroph adenoma of the pituitary gland: a clinicopathologic analysis of 100 cases. Mayo Clin Proc 1996; 71: 649-56.

55. Yamada S, Kovacs K, Horvath E, Aiba T. Morphological study of clinically nonsecreting pituitary adenomas in patients under 40 years of age. J Neurosurg 1991; 75: 902-5.

56. Freda PU, Beckers AM, Katznelson L, Molitch ME, Montori VM, Post KD, Vance ML; Endocrine Society. Pituitary incidentaloma: an endocrine society clinical practice guideline. J Clin Endocrinol Metab 2011; 96: 894-904.

57. Donckier JE, Gustin T. Pituitary incidentaloma: to operate or not to operate? Acta Chir Belg 2012; 112: 255-60.

58. Randall BR, Kraus KL, Simard MF, Couldwell WT. Cost of evaluation of patients with pituitary incidentaloma. Pituitary 2010; 13: 383-4.

\section{Address for correspondence}

\section{Nadia Sawicka}

Department of Endocrinology, Metabolism and Internal Medicine

Poznan University of Medical Sciences

Przybyszewskiego 49

60-355 Poznań, Poland

e-mail: nyha@o2.pl

Submitted: 4.03.2013

Accepted: 18.04.2013 